8-31-2017

\title{
The spiraling and spillover of misconduct: Perceived workplace bullying, subclinical psychopathy, and businesspersons' recognition of an ethical issue
}

\author{
Sean R. Valentine \\ University of North Dakota, sean.valentine@UND.edu \\ Sheila K. Hanson \\ University of North Dakota, sheila.hanson@UND.edu \\ Gary M. Fleischman
}

\section{How does access to this work benefit you? Let us know!}

Follow this and additional works at: https://commons.und.edu/man-fac

Part of the Advertising and Promotion Management Commons

\section{Recommended Citation}

Sean R. Valentine, Sheila K. Hanson, and Gary M. Fleischman. "The spiraling and spillover of misconduct: Perceived workplace bullying, subclinical psychopathy, and businesspersons' recognition of an ethical issue" (2017). Management Faculty Publications. 2.

https://commons.und.edu/man-fac/2

This Article is brought to you for free and open access by UND Scholarly Commons. It has been accepted for inclusion in Management Faculty Publications by an authorized administrator of UND Scholarly Commons. For more information, please contact und.commons@library.und.edu. 


\title{
The Spiraling and Spillover of Misconduct: Perceived Workplace Bullying, Subclinical Psychopathy, and Businesspersons' Recognition of an Ethical Issue
}

Sean R. Valentine 1 \& Sheila K. Hanson2 \& Gary M. Fleischman3

\begin{abstract}
Workplace bullying can potentially spiral into numerous counterproductive behaviors and negative organizational outcomes. Therefore, the purpose of this study was to determine the degree to which increased perceptions of workplace bullying were associated with stronger expressions of (subclinical) psychopathic traits and weakened ethical decision making. Data were collected from national and regional samples of selling and business professions using a self-report questionnaire that contained relevant measures and an ethics scenario, and structural equation modeling was employed to investigate the proposed relationships. Findings indicated that perceived workplace bullying operated through psychopathy to influence the recognition of an ethical issue (or full mediation). The implications of these findings are discussed, along with the study's limitations and suggestions for future research.
\end{abstract}

\section{Keywords}

Workplace bullying, Spiraling, Psychopathy, Ethical decision making

In a typical workday, there are numerous motivations and opportunities for employees to mistreat each other. From less overt forms of misbehavior such as badmouthing, aggressive communication, and politicking to more serious types that include coercion, subversion, and sabotage, workplace bullying has emerged as a prevalent challenge in different organizations and professional environments (e.g., Aquino and Thau 2009; Hutchison et al. 2009; Lutgen-Sandvik et al. 2007; Mikkelsen and Einarsen 2001; Salin 2001). Bullying has even been explored in the academic environment given its frequency within the ranks of universities (Giorgi 2012; McKay et al. 2008; Zabrodska and Kveton 2013).

Research shows that a number of factors can cause such misbehavior. High performance expectations related to pay (Samnani and Singh 2014), stressful and/or chaotic workplaces (Baillien et al. 2011; Heames et al. 2006; Hodson et al. 2006), and limited resources can encourage individuals to be self-interested and competitive, and when these characteristics are coupled with low management oversight and/or power differentials (Hodson et al. 2006), interpersonal conflict and bullying can occur. A toxic, corrupt, or unethical work environment can also precipitate bullying (McKay et al. 2008; Hutchison et al. 2009; Valentine et al. 2015; Vickers 2014). Additionally, prior research identifies many negative outcomes of bullying such as poor work attitudes/responses, high stress/burnout, and decreased emotional, psychological, and physical well-being (Aquino and Thau 2009; Bowling and Beehr 2006; Giorgi 2012; Mayhew et al. 2004; Parzefall and Salin 2010).

A particularly destructive consequence of workplace bullying involves a spiraling effect that encourages targets to harm coworkers as a result of their own negative work experiences. 
According to Salin (2003, p. 1217), “...bullying can often be described as a self-reinforcing or spiraling process, building on vicious circles (cf. Andersson and Pearson 1999). In addition, bullying and other forms of anti-social behaviour may also cascade and spawn secondary bullying spirals, either through modeling or displacement (cf. Pearson et al. 2000)." Such misbehavior can also "spill over" from one area of a company to others as individuals interact with different employees (McKay et al. 2008). This implies that bullying can be repeated when it is experienced in a workplace impacted by negative employee interactions, even in other office domains. Professional and organizational contexts can exacerbate these problems with cultural characteristics that allow bullying to occur, be learned, and be reciprocated (i.e., excessive informality, preferences for aggressive behaviors/humor, and low morale), or by employing "hands off" or unfair leadership styles that fail to properly supervise the actions of employees (Boddy 2011; Harvey et al. 2009; Pilch and Turska 2015; Salin 2003). Consequently, certain occupations may be prone to such misconduct.

Harmful workplace behaviors appear to be significant concerns in the sales profession. The field of selling is often characterized by a variety of individual deviant behaviors, and according to Darrat, Amyx, and Bennett (2010, p. 239), this “....alarming prevalence of deviance among salespeople may be due, in part, to an inherent leniency toward deviant behavior within the sales industry." Of particular relevance to this study are the acts of interpersonal deviance that can be exhibited by salespersons, which can include mistreating work associates, taking credit for other people's contributions, and blaming others for negative outcomes (Jelinek and Ahearne 2006). Social undermining may also be a problem in the sales profession, behavior that includes “...intentional offenses aimed at destroying a salesperson's favorable reputation, his or her ability to accomplish sales-related work, or his or her ability to build and maintain positive relationships with supervisors, coworkers, and customers as boundary spanners" (Yoo and Frankwick 2013, p. 80). In this sense, aggressive behaviors that harm coworkers have the capacity to spiral and spillover in the sales industry, as well as other occupations, thus adversely changing employees' attitudes about what is considered acceptable conduct.

Negative bullying experiences that spiral out of control may also create a toxic work environment that harms an organization's ethical context. For example, Power et al. (2013) determined that cultures emphasizing achievement and accomplishments may be more accepting of bullying, which could lead to a negative culture in which bullying becomes the norm. Furthermore, Giorgi et al. (2015) found a curvilinear relationship between bullying and job satisfaction, which suggests that increased exposure to bullying is related to (at some point) incrementally higher employee job satisfaction. Over time, bullying may not be viewed so negatively by employees, as they may perceive that some degree of bullying is necessary for high job performance.

These attitudinal changes are likely exhibited through a variety of antisocial and counterproductive tendencies. For instance, workplace bullying would seem to negatively impact how individuals prefer to interact with and treat their coworkers, setting the stage for the reciprocal and displaced mistreatment of others. In the organizational context, "it is contended that the external environment can contribute to the acquisition and maintenance of aggressive 
and bullying behaviors" (Harvey et al. 2009, p. 33). Past work also indicates that bullying experiences may encourage individuals to behave aggressively toward others (Hauge et al. 2009; Matthiesen and Einarsen 2007).

But what negative psychological processes motivate persons to bully others in response to their negative job interactions? The answer to this question likely resides within a group of personality traits that may be reinforced based on bullying experiences. According to Pilch and Turska (2015, p. 85):

In the case of the personality of perpetrators, the set of significant traits which may prove to be crucial for understanding the group specificity is the Dark Triad of personality (Machiavellianism, subclinical psychopathy, and subclinical narcissism) (Paulhus and Williams 2002). Despite their distinct difference, these traits are related by treating people like objects, manipulativeness, and lack of empathy, which favors undertaking of the activities classified as bullying (Baughman et al. 2012).

Of these three traits, psychopathy, which can motivate individuals to act ruthlessly and cold toward multiple target individuals, may be the most strongly associated with bullying because the two factors represent a common underlying set of negative behavioral tendencies that directly harm others (Baughman et al. 2012; Boddy 2011). While Machiavellianism and narcissism can lead to negative interactions with others, these traits may share comparatively weaker relationships with overt/serious forms of aggression such as bullying than does psychopathy (see for example Baughman et al. 2012; Pilch and Turska 2015), as well as be viewed as less undesirable (Rauthmann and Kolar 2012), possibly indicating that psychopathy is the most socially disruptive characteristic in the Dark Triad. Consequently, as a personality style psychopathy may be manifested through an "acting out" of negative tendencies that precipitate (and possibly reinforce) workplace bullying, thus encouraging a spiraling/spillover of misconduct in the workplace.

There is also reason to believe that the spiraling/spillover of bullying and the reinforcement of (subclinical) psychopathy personality styles negatively affect the ethical decisions that are triggered when employees are mistreated. Using multiple ethical lenses (i.e., deontology, utilitarianism, fairness, etc.), workplace bullying and the actions closely associated with psychopathy are unethical because organizations are ultimately harmed by a reliance on aggression as acceptable behavior (Boddy 2011; Harvey et al. 2009). These norms likely decrease individuals' ability to make ethical decisions because they are impacted by a negative work environment and behavioral tendencies. Harvey et al. (2009) presented a framework for understanding bullying in international business, which highlights how the work context can encourage bullying and modify employees' behavioral tendencies based on observed misconduct. These linkages suggest that unethical decision making is driving an increased willingness among individuals to mistreat others. It is known that:

...employees solve ethical dilemmas based on their individual characteristics, the organizational culture in which they are embedded and the resulting 'realities' of 
the work environment, and their relationships with others in the organization. If any of these elements deficient or aberrant behavior in nature bullying can occur. Moreover, if the situation is not adequately addressed by management, bullying can become an accepted 'ethical' behavior in global organizations (Harvey et al. 2009, p. 30).

Research also shows that traits such as Machiavellianism and psychopathy are associated with increased workplace bullying and other dysfunctional actions (Baysinger et al. 2014; Pilch and Turska 2015), which implies that employees' ethical decision making and behavioral choices are compromised when they are subjected to bullying, and that similar misbehaviors can be prompted by the unethical reasoning associated with negative behavioral tendencies.

Given these issues and concerns, the purpose of this study is to investigate the degree to which workplace bullying, psychopathy, and ethical decision making are interrelated in organizations. While including these three factors in one study represents an ambitious effort, we believe that examining a more comprehensive model (instead of narrowing the scope of the investigation to just two variables) enables us to more effectively bring together distinct literatures and make a stronger contribution. In addition, the variables selected and relationships proposed more closely align with existing theory in the field of managerial ethics; for instance, many models of ethical reasoning indicate that decision making is influenced by both individual and contextual factors in an interactional sense (see Ferrell and Gresham 1985; Hunt and Vitell 2006; Jones 1991; Treviño 1986). It is therefore proposed that perceptions of organization-wide bullying encourage attitudes and behaviors consistent with psychopathy, which decrease the recognition that the mistreatment of a selling professional (presented in a sales scenario) is unethical. While the presence of reverse causation is certainly plausible (i.e., psychopathy $\rightarrow$ workplace bullying), we posit that broad perceptions of a work environment characterized by bullying (as opposed to more immediate and negative target experiences) have the capacity to encourage employee behaviors related to psychopathy, which result in weakened ethical reasoning. As noted previously, we also contend that the selling profession is an appropriate context for exploring these linkages because it is adversely impacted by a variety of ethical issues (see Caywood and Laczniak 1986; Ferrell et al. 2007; Hoffman et al. 1991; Seevers et al. 2007; Serviere-Munoz and Mallin 2013; Tellefsen and Eyuboglu 2002; Wotruba 1990), including interpersonal conflict and deviant behavior that is closely related to workplace bullying (Darrat et al. 2010; Jelinek and Ahearne 2006; Yoo and Frankwick 2013). In addition, “...there is relatively little known about negative salesperson behaviors" (Jelinek and Ahearne 2006, p. 327), and "...little work has explored salesperson negative or dysfunctional behavior and what causes this negative behavior" (Yoo and Frankwick 2013, p. 79), so investigating the proposed relationships within the selling context enables this study to make a more substantial contribution to the literature.

This research is important and relevant for several reasons. First, it represents one of the first examinations of the possible connections among workplace bullying, subclinical psychopathy, and individual ethical decision making. Valentine et al. (2017) found, among other relationships identified, that bullying experiences were positively related to psychopathy, and that psychopathy was negatively related to the perceived importance of an ethical issue and ethical 
intention. However, this present study examines a broader, more culture-centric measure of workplace bullying, or bullying index, as well as a different component of ethical decision making, recognition of an ethical issue, to investigate the notion that negative social interactions in the workplace have the capacity to harm multiple stages of individual ethical reasoning. Similar to other culture-based measures, use of an index that taps employees' perceptions of organization-wide bullying is particularly appropriate because, compared to more narrow measures of individual bullying experiences, it should provide a better gauge of the sociocultural norms (and subsequent misconduct) that occur throughout a company. Key to this investigation, perceptions of these behavioral norms should be better positioned to influence individuals' decisions about how to think and behave from an ethical standpoint.

By exploring these key relationships, this study also has the potential to fill important theoretical and empirical gaps at the crossroads of the business ethics and management literatures. A number of perspectives such as social exchange theory (i.e., perceived psychological contract breach, injustice, low organizational support) (Parzefall and Salin 2010), social learning theory (Harvey et al. 2009; Salin 2003), and Novak's (1998) learning theory (Altman 2010) have been used to explore the proliferation of workplace bullying, and testing the study's proposed relationships provides additional evidence that these theoretical lenses are useful tools for understanding why such aggression occurs in organizations. Additionally, providing evidence that perceived workplace bullying and reinforcement of subclinical psychopathy function in concert to harm ethical reasoning provides further understanding of how bullying can negatively spiral into other dysfunctional tendencies in the workplace. According to Parzefall and Salin (2010, p. 762), "to date very limited attempts have been made to understand the mechanisms and processes through which the experience of workplace bullying evolves and translates into negative reactions from targets and, above all, from bystanders. This is an important issue, as the experience of bullying ultimately influences evaluations of the employment relationship and its quality as a whole." The following section presents the relevant literature and hypotheses.

\section{Literature Review}

\section{Workplace Bullying and Psychopathy}

Definitions of workplace bullying commonly revolve around negative verbal or nonverbal behaviors directed at target individuals, as well as the outcomes of these negative acts and harmful effects on victims (Einarsen et al. 1994; Saunders et al. 2007). Bullying may range from subtle comments to aggressive behavior. Less severe forms of bullying (e.g. snide comments) that occur frequently may be just as harmful as more serious bullying experiences (e.g. humiliation), where the perceptions of negative and inappropriate behavior cause harm (Baron and Neuman 1998; Saunders et al. 2007). Mayhew et al. (2004) determined that, similar to assault, even covert types of violent acts in companies such as bullying could cause emotional problems for victims. 
Beyond harming targets, bullies who perpetrate negative behaviors may influence others, including those who have witnessed the bullying (Samnani and Singh 2012). For instance, perceptions that bullying proliferates at work can negatively impact job satisfaction (Valentine et al. 2015). These connections imply that bullying might be learned experientially though negative work encounters and interactions (Altman 2010). As social learning theory suggests, modeling and imitating workplace bullying can help reinforce and spread negative effects (Salin 2003). Novak's (1998) learning theory implies that experiences aid in the development of differing perceptions of workplace bullying, which can result in greatly varied reactions to it (Altman 2010). There may be significant motivations for witnesses of bullying to follow suit if they perceive that bullying yields positive rewards in the workplace (Boddy 2014). This may be particularly true if the organizational environment is viewed as a corrupt system that legitimizes the mistreatment of employees (see Hutchison et al. 2009; Vickers 2014).

Like bullies, psychopaths of all types (i.e., "clinical," "subclinical," "corporate," "successful," etc.) are also predisposed to cause harm to others (e.g., Boddy 2011; Hare 1994, 1999a, b; Stevens et al. 2012). Of all elements of the dark triad, psychopathy is often the most closely related with violent, dangerous, aggressive (O'Boyle et al. 2012; Rauthmann and Kolar 2012), and destructive workplace behavior (Boddy 2011). Psychopathy has been conceptualized as a disorder (Blair 2007; Lynam et al. 2007) that involves emotional dysfunction (e.g. an absence of empathy) and antisocial behavior (Blair 2007; Hare 1994, 1999a, b). Research into the etiology of psychopathy has distinguished two types (i.e., factors), including primary and secondary psychopathy (Yildirim and Derksen 2015). Primary psychopathy is considered a personal difference that is related to genetic origins, while secondary can be considered "an environmentally-contingent strategy," leading to psychopathic behavioral expression (Yildirim and Derksen 2015, p.18). Subclinical levels of secondary psychopathy, particularly the behavioral tendencies that are acted out in the corporate setting, are the focus of the current study.

Psychopaths, including those who exhibit subclinical levels of the characteristic and/or effectively function in companies, display a variety of potentially negative traits and behaviors such as an elevated sense of self-importance, shallow obsequiousness and charm, dishonesty, a charismatic and manipulative nature, decreased empathy, and an inability to accept personal responsibility for their misdeeds (e.g., Boddy 2011; Hare 1994, 1999b). In the general population, subclinical psychopathy, is estimated to occur at base rates of $5 \%$ to $15 \%$ (LeBreton et al. 2006), so the incidence is higher than clinical psychopathy traits and behaviors manifested at clinical levels (i.e. those individuals with diagnosable, severe impairment), which occurs at base rates of around 1\% (Hare 1999a, b). The rare clinical levels of psychopathy may be most closely associated with Antisocial Personality Disorder, diagnosable only when sufficient criteria as found in the DSM 5 (APA 2013) are met. Even at subclinical levels, psychopathy is viewed as the most malicious of the Dark Triad (Rauthmann and Kolar 2012). Cognitive and neuropsychologists have identified the underlying neuropsychological mechanisms of the amygdala, which modulates emotional responses, and the ventromedial prefrontal cortex, which plays a role in reasoning through potential negative consequences of behavior (Boddy 2011; Carlson 2014). Both the amygdala and ventromedial prefrontal cortex interact in moral 
reasoning, and that process may be impaired in the case of psychopathy (Blair 2007). Dysfunction and antisocial behaviors are some of the other negative consequences associated with psychopathy (Hare 1994).

These counterproductive tendencies can create many challenges in the workplace. In particularly, subclinical/corporate psychopaths are known to get their way through bullying behaviors such as coercion, abuse, humiliation, aggression and fear tactics (Babiak and Hare 2006; Boddy 2011). Psychopathic bullies do not feel remorseful, guilty, or empathic in relation to their behavior, lacking insight; in fact, they may be unable or unwilling to control their behavior, even when more moderate behavior would ultimately be more advantageous (see Babiak and Hare 2006).

Like bullies on the playground in childhood, psychopathic tendencies and bullying behavior in the workplace may be connected. The notion of workplace psychopaths has gained traction to explain the incidence of workplace bullying (Caponecchia et al. 2012). The observable outcomes of bullying behavior and the attitudes and traits of subclinical psychopathy suggest theoretical overlap between bullies and subclinical psychopaths (Boddy 2011; Harvey et al. 2007). Boddy (2011) found a high positive correlation $(r=0.939)$ between corporate psychopaths being in the workplace and the degree of perceived bullying (i.e. "witnessing unfavorable treatment of others at work"), which supported prior work demonstrating that individuals scoring high in measures of psychopathy were more likely to engage in bullying behavior (Nathanson et al. 2006). Certainly, bullies and psychopaths can be different individuals, yet there does seem to be considerable overlap between the two patterns/profiles. For example, Babiak and Hare (2006) found that around 29\% of corporate psychopaths are also bullies. Further, Boddy (2014) evaluated the amount of bullying in organizations based on managerial type (i.e. "normal," "dysfunctional," and "psychopathic") and determined that $35.2 \%$ of all bullying was related to corporate (i.e. subclinical) psychopaths.

Given this evidence, it can also be argued that exposure to workplace bullying may precipitate psychopathic tendencies in employees. The spiraling/spillover effect of bullying in organizations can create a culture that condones it, encouraging employees to learn and utilize such misconduct as an acceptable form of interaction with colleagues (e.g., Altman 2010; Harvey et al. 2009;

Salin 2003). The negative social exchanges that are experienced when bullying is widespread can also create a prevailing perception among some individuals that equity, justice, and other ethical standards are not honored within a company (e.g., Parzefall and Salin 2010), thus encouraging them to adopt patterns associated with psychopathy for the purposes of self-benefit/interest. Taken together, these points lead to the following hypothesis:

Hypothesis 1: Stronger perceived workplace bullying is associated with increased psychopathy.

\section{Psychopathy and Recognition of an Ethical Issue}

While psychopaths who lack a conscience may experience legal problems, psychopaths who possess subclinical levels of psychopathy may work undetected and even successfully within the 
workplace (Boddy et al. 2010). Successful psychopaths can exhibit poor ethical decision making (Boddy et al. 2010), and when they preside in leadership and other positions of power, may negatively influence others (Boddy 2011). When leadership and management include subclinical psychopaths, modeling unethical behavior to employees is more likely (Boddy 2006).

Subclinical psychopaths are known for maximizing their own wealth and power and can make impulsive decisions in their own self-interest without carefully considering the long-term impacts to the organization (Boddy 2006). Further, lacking conscience and a sense of morality, subclinical psychopaths are often unaware of the problems related to decisions that are "immoral, unethical, contrary to accepted codes of professional practice, or outright illegal" (Boddy 2006, p. 1470).

Ethical decisions should be particularly affected by patterns of psychopathy. The ethical decision-making process is typically conceptualized as a series of mental and behavioral steps that occur sequentially as employees face ethical dilemmas at work (see Ferrell and Gresham 1985; Ferrell et al. 2007; Hunt and Vitell 2006; Jackson et al. 2013; Jones 1991; Rest 1986; Treviño 1986; Wotruba 1990 for variations of the basic framework). Individuals first recognize that a situation contains an ethical issue before evaluating any potential problems; this first step is viewed as a critical component of ethical reasoning because it precipitates other more advanced stages of decision making (e.g., Rest 1986). The next step involves making judgments of the ethicality of a situation based on different paradigms such as equity, fairness, justice, and social expectations (see Rest 1986; Reidenbach and Robin 1990). Once formalized, these judgments lead into intentions to behave consistently with previous evaluations. The final step is behaving according to previous judgments and intentions (Jones 1991; Rest 1986). Research indicates that these steps hold true in many different ethical situations (e.g., Barnett 2001; Barnett and Valentine 2004; Robin et al. 1996; Valentine and Barnett 2007; Valentine et al. 2010).

Prior research suggests that the neuropsychological makeup of individuals with psychopathic tendencies makes them challenged to follow the steps of the ethical reasoning process (Blair 2007; Carlson 2014). Within the construct of subclinical psychopathy are the underlying belief systems that may compromise the ethical reasoning process. Subclinical psychopaths are known to admire clever scams, feel justified in doing whatever they can get away with and would agree with the statement: "For me, what's right is whatever I can get away with" (Levenson et al. 1995, p. 153). In addition, Jackson et al. (2013) suggested in their framework of ethical decisionmaking dissolution that poor cognitive moral development, low ethical sensitivity, and a willingness to break rules among leaders, traits reflective of psychopathy, would negatively impact the recognition of ethical situations.

One study in particular provides compelling support for these relationships. Stevens et al. (2012) found that the link between psychopathy and unethical reasoning was mediated by the variable moral disengagement. In their study, a large sample of undergraduates reacted to four ethics vignettes based on typical organizational dilemmas (e.g., shortcuts in production, failing to highlight inaccuracies in financial documents, etc.) and were asked to indicate the likelihood that they would commit the unethical behaviors in the scenarios. As predicted, psychopathy was 
positively related to individuals' self-reported willingness to commit unethical acts (Stevens et al. 2012). Given the positive relationship between psychopathy and unethical decision making, it follows that as levels of psychopathy increase, recognizing an ethical issue, the first step in the ethical decision-making process, would decrease. The following hypothesis is therefore proposed:

Hypothesis 2: Increased psychopathy is associated with decreased recognition of an ethical issue.

\section{Workplace Bullying and Recognition of an Ethical Issue}

Workplace bullying has significant effects on both targets and observers in the workplace. As mentioned earlier, bullies and psychopaths can be different people, but there appears to be a noteworthy overlap in expressed deviant behavior (Babiak and Hare 2006; Boddy 2014). Therefore, both victims and observers of this dysfunctional behavior are, over time, likely to incorporate these behaviors themselves and/or come to accept them as normalized organizational behavior (Giorgi et al. 2015), which triggers the spiraling/spillover of misconduct.

A number of potential affective/attitudinal (e.g. job satisfaction and commitment), health/wellbeing (e.g. mental and physical health), and behavioral outcomes (e.g. performance) have been associated with bullying (e.g., Giorgi 2012; Nielsen and Einarsen 2012). Mayhew et al. (2004) found that violent acts at work such as bullying could precipitate severe emotional trauma in employees. Unfortunately, individuals may experience a constellation of these negative outcomes, which could fundamentally affect other work responses. Successful psychopaths who bully, and others who adopt similar behaviors, may focus on short-term gains in individual performance outcomes to rationalize their actions (Babiak and Hare 2006), while long-term cumulative impacts of bullying at the organizational level are likely to be detrimental to a company and its performance (Samnani and Singh 2012; Vega and Comer 2005). Giorgi (2012) indeed determined that workplace bullying was negatively related to a positive organizational climate.

When bullying spirals and/or spills over, there is reason to believe that ethical dissolution would result from an egoistic fixation on individual gains at the expense of others, and that these preferences can be driven by unethical corporate cultures, highly competitive workplaces, and social networks that allow and/or encourage dysfunctional behavior (Jackson et al. 2013). It has been proposed that bullying is a reflection of corruption in organizations (Hutchison et al. 2009; Vickers 2014), and a work environment affected by such corruption should function in a way counter to generally accepted ethical norms. According to McKay et al. (2008, p. 92):

Systematic bullying, hazing and abuse generally are identified with poor, weak or toxic organizational cultures. Cultures that are toxic have stated ethical values that are espoused but not employed, and other non-ethical values which are operational, dominant, but unstated. Such cultures thrive when good people are silent, silenced, or pushed out; when bad apples are vocal, retained, promoted, and 
empowered; and when the neutral majority remain silent in order to survive.

Those who are most successful in such a toxic culture are those who have adapted

to it, or adopted it as their own.

With regard to ethical decision making, deficits may occur in a person's ability to recognize an ethical issue in situations where an unethical work environment motivates employees to adopt tendencies related to subclinical psychopathy and bully others. Given the constitutional features of lack of remorse, deception, unethical and antisocial behaviors (Neumann and Hare 2008), subclinical psychopathy may provide an explanatory mechanism in the pathway between workplace bullying and ethical reasoning. Social learning suggests that employees learn negative behavior (i.e. bullying) from their superiors (Bandura 2006; Boddy 2014). If those influential leaders and managers are both bullies and subclinical psychopaths, or they possess traits and preferences that are consistent with these behavioral patterns (disregard for rules, poor ethics, lack of consideration, short-term thinking; see Jackson et al. 2013), employees could also learn normative psychopathic responses to their decision-making at work, starting with ethical issue recognition. In essence, employees learn accepted workplace norms of deviant behavior (Giorgi et al. 2015) that manifests as insensitivity to ethical issues. Consequently, mediation is proposed in the following hypothesis:

Hypothesis 3: The relationship between perceived workplace bullying and recognition of an ethical issue is mediated (either fully or partially) by psychopathy.

\section{Method}

\section{Data Collection}

Using contact information secured from a third-party commercial provider and a questionnaire containing ethics and employment-related items, data were collected from a national sample of 3000 selling and business employees.1 Once again, we contend that investigating issues relating to bullying and psychopathy are especially relevant to selling professionals because of their competitive, boundary spanning work environment that is replete with ethical dilemmas and interpersonal misbehavior (Darrat et al. 2010; Jelinek and Ahearne 2006; Valentine et al. 2015; Yoo and Frankwick 2013). A cover letter, questionnaire, and postage-paid return envelope were initially mailed to employees, and 95 questionnaires were received from this first wave of mailings. After a period of time spanning roughly three months, a second wave was mailed to the same individuals, and 43 forms were returned for a total of 138 questionnaires and a response rate of $4.73 \%$ taking into consideration ineligible forms. 2 Based on an assessment of analysis of variance models, cross tabulations, and chi-square statistics (Armstrong and Overton 1977), differences were not identified across the two waves for the variables assessed in this study, leading to the conclusion that nonresponse bias was not problematic. 
To obtain more information, data were also collected from a convenience sample of individuals employed at different organizations with locations in a southern area of the United States. The sampling frame was defined broadly to include individuals who participated in various organizational selling functions, but several other employees not involved in selling also completed the questionnaire. Subjects were provided a copy of the questionnaire, and in some cases, they were given extra copies so that additional coworkers could be recruited to participate. A total of 246 questionnaires were secured from this data collection round, which generated a total sample of 384 usable questionnaires. The answers provided on several sales demographic items indicated that well over 300 of these employees were engaged in selling as part of their jobs (made sales calls, had sales accounts, etc.).

The sample members had a mean age of 38.66 years. Almost $59 \%$ of individuals were male, nearly $71 \%$ were white, and just over $52 \%$ were married. Half of individuals had some college and slightly over $22 \%$ had a Bachelor's degree. Almost $80 \%$ were employed full-time in their organizations, and their average job tenure was 8.21 years. Almost $41 \%$ were employed as sales/marketing managers, and just over $10 \%$ were general managers. Forty-four percent of firms operated in the wholesale/retail industry, over $15 \%$ operated in manufacturing/construction, and over $9 \%$ operated in services. Over $51 \%$ of companies employed fewer than 100 persons. These characteristics suggest that the combined samples provided a useful cross-section of businesspersons for this study, many of whom performed sales-oriented roles in their jobs.

\section{Measures}

Perceived workplace bullying was measured with the five-item Bergen Bullying Index (Einarsen et al. 1994). This scale provides a broad assessment of workplace misconduct, and it demonstrates high internal consistency reliability with coefficient alphas ranging from .82 to .89 (Einarsen et al. 1994; Matthiesen and Einarsen 2007; Valentine et al. 2015). Sample items include "Bullying is a serious problem at my workplace" and "Bullying at my workplace reduces my work motivation." Responses were provided on a seven-point scale anchored with 1 (Strongly disagree) and 7 (Strongly agree), and higher item values indicated increased perceptions of workplace bullying.

Subclinical psychopathy was evaluated with six items (see Valentine et al. 2017) taken from the primary subscale of the Levenson Self-Report Psychopathy Scale (Levenson et al. 1995; Lynam et al. 1999), which was developed for use with non-institutionalized populations with a coefficient alpha of .82 (Levenson et al. 1995). The overall self-report instrument consists of two subscales, primary and secondary. The primary scale is comprised of sixteen items and was designed to measure core affective and interpersonal features, while the secondary scale is comprised of ten items and was designed to assess socially deviant attitudes and traits. Items from the secondary psychopathy subscale, designed to assess impulsivity and a self-defeating lifestyle (Levenson et al. 1995), were not included on the questionnaire because this subscale is more associated with antisocial and criminal behavior (Smith and Lilienfeld 2013), often connected to clinical levels of psychopathy. 
Responses on the sixteen items were given on a seven-point scale anchored by 1 (strongly disagree) and 7 (strongly agree); items were coded in a direction to show increased self-report psychopathy. Since the measure was being used to collect data from a unique, (mostly) salesoriented population of business professionals, evaluation of the scale's measurement properties was deemed necessary. Consequently, the final set of six items utilized were selected based on previous research (Valentine et al. 2017) and the results of two factor analyses using principal components extraction, with the final model producing a single-factor solution with loadings above .62, an eigenvalue of 3.19, and 53.15\% of explained variance. Sample items of the scale are "I tell other people what they want to hear so that they will do what I want them to do" and "In today's world, I feel justified in doing anything I can get away with to succeed."

Similar to many other examinations of organizational ethics (e.g., Alexander and Becker 1978; Barnett 2001; Barnett and Valentine 2004; Reidenbach and Robin 1990; Valentine and Barnett 2007), this study relied on an ethical scenario to trigger subjects' ethical reasoning (see Valentine et al. 2017). This particular scenario highlighted a situation in which a salesperson (Kim) is mistreated by a coworker (Jocelyn) who exhibits behaviors related to psychopathy and workplace bullying:

"Situation: Kim is a seasoned salesperson in an office supply firm that services many large corporate clients. A year ago, she was given several new sales accounts that had high potential, mainly because of her seniority in the sales department, as well as her popularity, easy-going nature, and preferences for teamwork (i.e., she sometimes gives sales leads away to help struggling associates). Unfortunately, she has been unable to sell enough merchandise to these new clients, and her current level of sales performance only "meets expectations" according to recent appraisals received from her sales manager. Jocelyn, a relatively new member of the sales department, subscribes to a different approach to selling that involves individualistic and assertive tactics, excessive networking with others, and impression management around important people, qualities that have often enabled her to get good sales leads and assignments and to effectively close deals. Jocelyn is upset because she thinks that Kim is not selling enough given her good sales leads, she's too concerned about getting along with others, and she's not political enough. Consequently, Jocelyn believes that Kim's new accounts should be assigned to her to oversee and manage.

Actions: Jocelyn meets individually with members of the sales department to convince them that Kim's new accounts should be assigned to her. While many disagree with Jocelyn, she convinces a core group of salespeople, including the sales manager, that Kim's new clients should be given to her, which occurs during Kim's next performance appraisal. Feeling empowered by this decision, Jocelyn begins to ignore, isolate, and criticize those who disagreed with her, while at the same time strengthening her relationships with those who supported her." 
Recognition of an ethical issue was measured with one item that asked respondents whether Jocelyn's actions in the scenario involved an ethical issue, and responses were provided on a seven-point semantic differential scale anchored by 1 ("Completely disagree her actions involve an ethical issue") and 7 ("Completely agree her actions involve an ethical issue"). Higher item scores indicated increased ethical issue recognition.3

Several variables were also included as controls in the analysis. Ethics research can be negatively impacted by socially desirable responding given issue sensitivity (Randall and Fernandes 1991). Strahan and Gerbasi (1972) developed and validated a shortened ten-item scale from the original 33 item Crowne and Marlowe (1960) social desirability scale. The scale was again validated by Fischer and Fick (1993). We employed this scale to assess socially desirable tendencies in subjects. Sample items are "I have never been irked when people expressed ideas very different from my own" and "I have never deliberately said something that hurt someone's feelings." Items were rated with a seven-point scale anchored by 1 (Strongly disagree) and 7 (Strongly agree) and coded so that higher scores showed increased social desirability. All item scores were added together and divided by the total number of items to obtain an overall composite score. The scale's coefficient alpha was .64. In addition, a dichotomous variable indicating the type of sample ( 1 = national sample, 2 = regional sample) was also included as a control because multiple response differences were identified across these two groups. Finally, the hours of ethics training that individuals had received from their organizations in the last year was included as a control variable because training is thought to mitigate bullying and other counterproductive behaviors at work (Altman 2010).

\section{Analysis}

Using structural equation modeling and the AMOS software, the measurement characteristics of the focal constructs were evaluated. A measurement model containing the latent focal variables, the associated observed items, and the observed focal and control variables was specified in a confirmatory factor analysis (CFA). Composite reliability and variance-extracted scores were estimated for the latent focal variables using the associated observed item standardized parameters (Hair et al. 1998). The potential for common method bias was also assessed by specifying a single-factor model (Podsakoff et al. 2003); all of the observed items and observed focal/control variables were loaded on one latent factor to determine whether such a model produced acceptable fit statistics and item loadings. Variable descriptive statistics and correlations were then estimated in SPSS using the observed control and focal variables, as well as the composite scores derived from averaging the relevant items for the latent variables; reliability statistics (coefficient alphas) were also evaluated. Finally, hypothesis testing was conducted in AMOS by specifying a full mediation structural model that contained the latent focal variables, observed items, and observed focal/control variables. A second partial mediation model was then specified by adding an additional constraint (a path between the independent and dependent variables) to the structural framework and determining whether there was a significant improvement in model chi-square. 


\section{Results}

\section{Confirmatory Factor and Single-Factor Models}

The model fit statistics for the CFA were acceptable (see Table 1). In addition, the observed items were related to the latent focal variables $(\mathrm{p}<.001)$, and the standardized estimates were above .50 (see Fig. 1). There was a number of significant covariances, and the relationships were in the directions proposed. The composite reliability scores for workplace bullying and psychopathy were .88 and .82 , and the variance-extracted estimates were .61 and .44 . The variance-extracted estimates for the workplace bullying and psychopathy variables were higher than their associated squared correlation, which indicated reasonable discriminant validity (Fornell and Larcker 1981). The single-factor model did not produce acceptable fit statistics (see Table 1), which suggested that common method bias was likely not a concern.

\section{Table 1}

Model fit statistics

\begin{tabular}{|l|c|c|c|c|c|c|c|c|}
\hline Model & $\boldsymbol{x}^{\mathbf{2}}$ & $\boldsymbol{d f}$ & $\boldsymbol{p}$ & $\boldsymbol{x}^{2} / \boldsymbol{d} \boldsymbol{f}$ & $\mathbf{N F I}$ & $\mathbf{I F I}$ & CFI & RMSEA \\
\hline $\begin{array}{l}\text { Confirmatory } \\
\text { factor analysis }\end{array}$ & 240.083 & 79 & .000 & 3.039 & .893 & .926 & .924 & .073 \\
\hline $\begin{array}{l}\text { Single-factor } \\
\text { model }\end{array}$ & 1382.840 & 90 & .000 & 15.365 & .383 & .399 & .391 & .194 \\
\hline $\begin{array}{l}\text { Full mediation } \\
\text { structural model }\end{array}$ & 241.037 & 80 & .000 & 3.013 & .892 & .925 & .924 & .073 \\
\hline $\begin{array}{l}\text { Partial mediation } \\
\text { structural model }\end{array}$ & 240.083 & 79 & .000 & 3.039 & .893 & .926 & .924 & .073 \\
\hline $\begin{array}{l}\text { Default models reported; } x^{2} / d f=\text { relative chi-square, } N F I \text { normed fit index, } \text { IFI incremental fit } \\
\text { index, } C F I \text { comparative fit index, } R M S E A \text { root mean square error of approximation; } N=384\end{array}$ \\
\hline
\end{tabular}




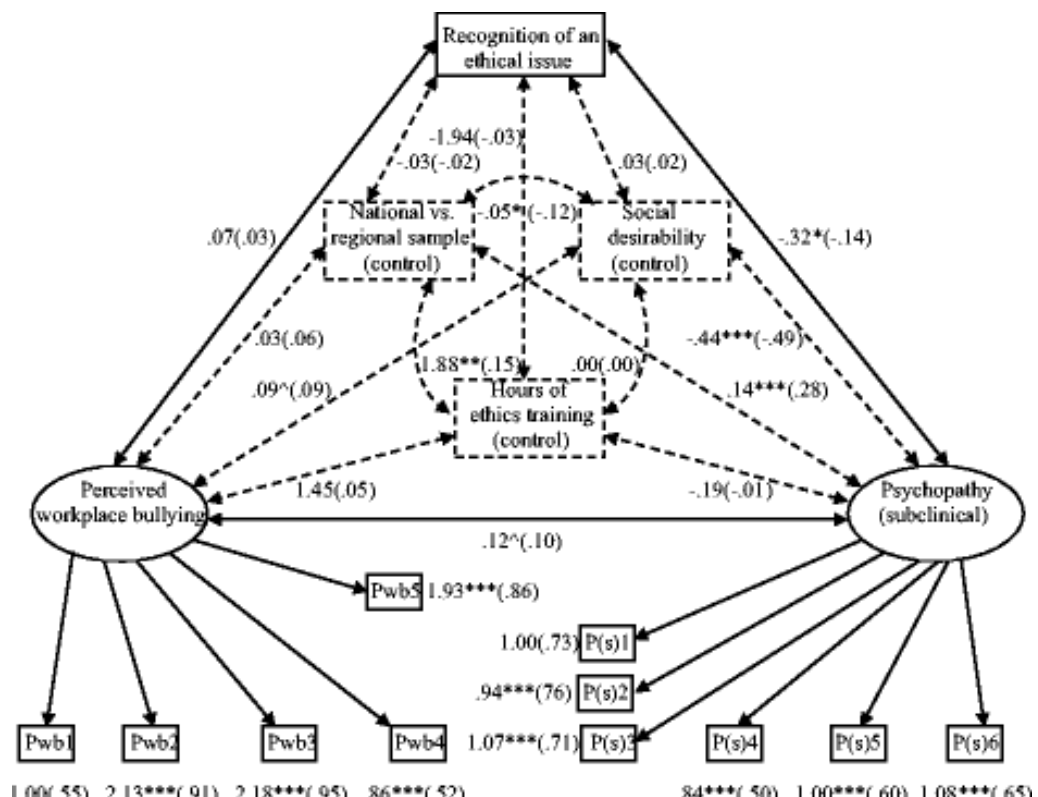

Fig. 1

Confirmatory factor analysis; notes: *** $p<.001, * * p<.01, * p<.05,{ }^{\wedge} p<.10 ; N=384$; standardized parameter estimates and correlations presented in parentheses (); dotted lines represent control variables and relationships

\section{Variable Descriptive Statistics, Correlations, and Reliability Statistics}

Table 2 presents the variable information and correlations. The mean value for perceived workplace bullying showed that such misconduct was not overly prevalent, and the mean value for psychopathy indicated that individuals exhibited only moderate tendencies toward socially aversive behavior. The mean value for ethical issue recognition indicated that individuals perceived only moderately that the scenario contained an ethical problem, and the mean value for social desirability indicated only modest tendencies toward impression management. The correlations indicated that perceived workplace bullying was positively related to psychopathy ( $\mathrm{p}$ $<.01)$ and the national vs. regional sample variable $(\mathrm{p}<.10)$ (individuals in the regional sample scored higher in perceived workplace bullying). Psychopathy was negatively related to recognition of an ethical issue $(\mathrm{p}<.05)$ and social desirability $(\mathrm{p}<.001)$ and positively related to the national vs. regional sample variable $(\mathrm{p}<.001)$ (individuals in the regional sample scored higher in psychopathy); the negative relationship between social desirability and psychopathy confirms the notion that individuals who score high in impression management (including individuals who exhibit traits consistent with psychopathy) will be reluctant to disclose any negative behavioral tendencies on a questionnaire. Sample type and social desirability were also negatively related $(\mathrm{p}<.05)$, with individuals in the regional sample scoring lower in social desirability than individuals in the national sample; sample type and hours of ethics training were positively related $(\mathrm{p}<.01)$, with individuals in the regional sample receiving comparatively more 
ethics training than individuals in the national sample. The multi-item scales had acceptable internal consistency reliability with coefficient alphas that were above .60 .

Table 2

Variable descriptive statistics, correlations, and reliability statistics

\begin{tabular}{|c|c|c|c|c|c|c|c|c|c|c|}
\hline Variable & $M$ & $S D$ & $N$ & $\alpha$ & 1 & 2 & 3 & 4 & 5 & 6 \\
\hline $\begin{array}{l}\text { 1. Perceived } \\
\text { workplace bullying }\end{array}$ & 2.84 & 1.88 & 373 & .88 & -- & & & & & \\
\hline $\begin{array}{l}\text { 2. Psychopathy } \\
\text { (subclinical) }\end{array}$ & 2.05 & 1.11 & 372 & .81 & $.17 * *$ & -- & & & & \\
\hline $\begin{array}{l}\text { 3. Recognition of an } \\
\text { ethical issue }\end{array}$ & 4.18 & 2.30 & 362 & -- & .03 & $-.12^{*}$ & -- & & & \\
\hline $\begin{array}{l}\text { 4. National vs. } \\
\text { regional sample } \\
\text { (control) }\end{array}$ & 1.64 & .48 & 384 & -- & $.10^{\wedge}$ & $.23 * * *$ & -.02 & -- & & \\
\hline $\begin{array}{l}\text { 5. Social } \\
\text { desirability } \\
\text { (control) }\end{array}$ & 4.80 & .87 & 364 & .64 & .08 & $-.42 * * *$ & .01 & $-.12 *$ & -- & \\
\hline $\begin{array}{l}\text { 6. Hours of ethics } \\
\text { training (control) }\end{array}$ & 7.72 & 25.57 & 331 & -- & .04 & -.02 & -.03 & $.15^{* *}$ & .01 & $\begin{array}{l}- \\
-\end{array}$ \\
\hline \multicolumn{11}{|l|}{$* * * p<.001$} \\
\hline$* * p<.01$ & & & & & & & & & & \\
\hline$* p<.05,^{\wedge} p<.10$ & & & & & & & & & & \\
\hline
\end{tabular}

\section{Structural Models}

Figure 2 presents the results of the mediation analysis. The full mediation structural model had acceptable fit statistics (see Table 1), and the observed items were all related to the latent focal variables $(\mathrm{p}<.001)$. After controlling for the impact of sample type, social desirability, and hours of ethics training, increased perceived workplace bullying was associated with increased psychopathy $(\mathrm{p}<.01)$, which provided support for Hypothesis 1 . Increased psychopathy was 
also associated with decreased recognition of an ethical issue $(\mathrm{p}<.05)$, providing support for Hypothesis 2.

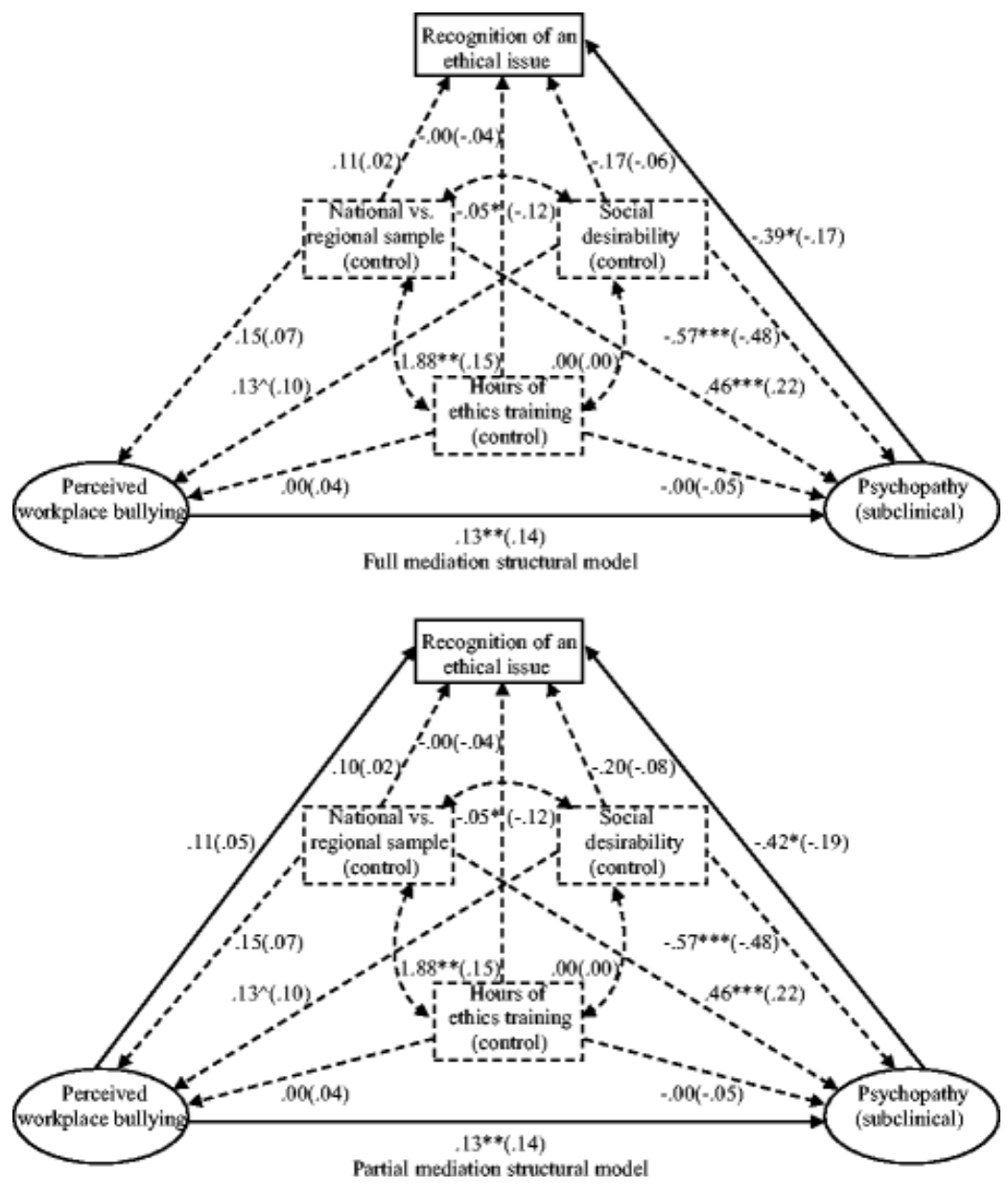

Fig. 2

Mediation analysis; notes: $* * * \mathrm{p}<.001,{ }^{*} \mathrm{p}<.01,{ }^{*} \mathrm{p}<.05, \wedge \mathrm{p}<.10 ; \mathrm{N}=384$; standardized parameter estimates and correlations presented in parentheses (); dotted lines represent control variables and relationships; parameter estimates associated with measurement model not shown

The partial mediation structural model also had acceptable fit statistics (see Table 1), and the observed items were once again related to the latent focal variables $(\mathrm{p}<.001)$. After controlling for the impact of the three control variables, increased perceived workplace bullying was associated with increased psychopathy $(\mathrm{p}<.01)$, and increased psychopathy was also associated with decreased recognition of an ethical issue $(\mathrm{p}<.05)$. These findings provided further support for Hypotheses 1 and 2. The additional constraint between perceived workplace bullying and recognition of an ethical issue that was added to the structural model was positive and insignificant $(\mathrm{p}=.3295)$, and this path did not produce a significant change in chi-square (chisquare difference $=.954$, d.f. difference $=1, p>.30$ ), which suggested that the full mediation structural model was the superior framework. Consequently, adequate statistical support was 
provided for Hypothesis 3, specifying that full mediation was present. Perceived workplace bullying operated through psychopathy to influence recognition of an ethical issue.4

\section{Synopsis of Findings}

Overall the findings provided additional insight and understanding regarding the complex relationships assessed. For example, Hypothesis 1 was supported, meaning that there was a positive association between perceived workplace bullying and subclinical psychopathy. This significant relationship suggests that employees with subclinical psychopathic tendencies are more likely to have experienced latent bullying, or vice versa. The results also supported Hypothesis 2, which proposed that employees with subclinical psychopathic tendencies exhibit weaker ethical reasoning. Therefore, such employees appear to be less likely to recognize an ethical issue when it arises compared to employees who do not possess such tendencies, probably because the unethical behavior in question is more consistent with behavioral norms of those with subclinical psychopathic tendencies. Finally, Hypothesis 3 focused on improving understanding of the complex interrelationship between perceived workplace bullying, subclinical psychopathic tendencies, and recognition of an ethical issue. Specifically, the findings underscored that the association between perceived workplace bullying and recognition of an ethical issue is fully mediated by psychopathy. Psychopathy appears to alter the relationship between bullying experiences and recognition of an ethical issue by both clarifying and governing the nature of the relationship between the two.

\section{Discussion}

The purpose of this study was to investigate the degree to which perceived workplace bullying, individual tendencies toward (subclinical/corporate) psychopathy, and ethical decision making are interrelated in business organizations. This inquiry is important because little is known about the complex interrelationships (Stevens et al. 2012) relating to how perceptions of bullying interact with psychopathy to influence the ethical reasoning, specifically ethical issue recognition. The study relied on a sample containing mostly sales-oriented professionals (supplemented with several other businesspersons) because the boundary spanning and highly competitive environment often found in the sales industry contains a variety of ethical challenges that may trigger bullying and other behaviors consistent with psychopathy (Darrat et al. 2010; Jelinek and Ahearne 2006; Valentine et al. 2015; Yoo and Frankwick 2013). This inquiry is especially concerned with the spiraling/spillover impact of bullying and psychopathy given the potential negative "ripple effect" that such negative deviance can advance in the workplace. This is important given that organization bystanders to bullying can be profoundly influenced by perpetrator-victim interactions (Lutgen-Sandvik et al. 2007; Parzefall and Salin 2010).

The results of this study have some bearing on the notion that workplace conflict is related to negative individual traits and decision making, which yields several important implications for managing incivility. The results indicated that persons who perceived increased bullying in the 
workplace and exhibited tendencies related to psychopathy were less able to recognize an ethical issue (related to this mistreatment of a work colleague) than were persons who perceived lower workplace bullying and did not possess traits consistent with psychopathy. Accordingly, employees susceptible to psychopathy may trigger or accentuate negative workplace activity, thus perpetuating a bully spiral or spillover. If one is unaware that an unethical dilemma exists, an individual is less likely to engage in appropriate moral reasoning to correct one's own behavior, thus increasing the spiraling and/or spillover of misconduct. Therefore, individuals who exhibit subclinical psychopathy, manifested in deceitful charm, impression management, and the manipulation of others, appear to be more prone to unethical reasoning in bullying situations, making them more likely to perpetuate bullying due to a lack of ethical sensitivity.

Given these results, managers in both the sales industry and other professions must determine how to shield organizations from a reduced ethical work context. If the workplace is already affected by widespread bullying and other unethical behaviors, then they must determine how the damage can be arrested and reversed. Clearly, leadership must minimize bullying and psychopathy before they spiral and spill over. Our findings suggest that organizations with toxic behavioral norms, including bullying and psychopathy, may employ individuals who are less able to recognize ethical issues related to such misconduct. Furthermore, past work indicates that if these negative behaviors are tolerated in organizations, the ethical context may eventually become toxic and viral in nature (Giorgi et al. 2015; Power et al. 2013). This is particularly true in cultures with a high-performance orientation, and where bullying and subclinical psychopathy are permitted to spread to a point that employees eventually perceive that such negative behavior is acceptable (Giorgi et al. 2015; Power et al. 2013). As stated previously, such an environment may exist within the field of sales (Darrat et al. 2010; Jelinek and Ahearne 2006; Yoo and Frankwick 2013). The lack of ethical awareness, a factor explored in this study, may be further exacerbated by an acceptance and tolerance of negative behaviors that are perceived to yield optimal performance. This chain of events could further trigger ethical denigration in a company and among salespeople that may ultimately lead to severe consequences. Therefore, if managers do not take action to mitigate concerns over such dysfunctional behaviors, organizations and their employees may ultimately be harmed.

\section{Initially Shielding the Organization}

One solution to shield organizations from bullying and psychopathy-related behaviors is to screen out job candidates and employees with negative personal characteristics and tendencies as part of the hiring process. Management must essentially identify individuals who are susceptible to psychopathy because they may be more likely to make poor decisions, bully others, and spread misconduct. Our findings also suggest that such persons are less likely to recognize an ethical issue when they face bullying situations. Levashina and Campion (2009) contend that employment interviews should be used as background checks to ensure that job candidates do not possess traits such as psychopathy that can trigger workplace aggression. Despite these efforts, such screening can be difficult to manage because subclinical psychopaths are often adept at charm, deception, and impression management (Harvey et al. 2009; Heames et al. 2006; 
Stevens et al. 2012), enabling them to provide socially desirable answers on individual assessments and other screening processes. Consequently, it may be relatively easy for persons who exhibit subclinical psychopathy to gain employment in organizations, even if the proper measures are taken.

\section{Reversing a Dysfunctional Culture}

If bullying and other beliefs/behaviors consistent with psychopathy are already commonplace in an organization, what can management do to mitigate or reverse the impact of these tendencies on corporate culture? A number of potential workable solutions are available, especially if bullies and/or psychopaths have not yet infiltrated management, which often establishes the overall ethical culture of the organization. Managers need to be themselves sensitive to the manipulative wiles of psychopaths and be able to recognize unethical workplace behavior when it occurs. A complicated part of identifying bullying and psychopathy is that those who act out in these ways are sometimes high performers, at least in a superficial sense, since they tend to promote themselves and their accomplishments, while undermining those of colleagues. These undesirable outcomes can be further exacerbated when management unwittingly rewards such misbehavior. Management may also be more likely to overlook misconduct when it produces seemingly positive outcomes for the organization, something that can occur in the sales industry (e.g., Darrat et al. 2010). Lack of management follow-through can lead to discouragement and resentment in victims and/or innocent observers (Heames et al. 2006). Making matters worse is the potential for bullying networks and alliances that enable individuals to support each other through enhanced rewards and opportunity (Hutchison et al. 2009), as well as the competitive nature of the sales work environment that can increase the potential for various deviant behaviors (Jelinek and Ahearne 2006).

Management should therefore consider employing an ethics officer who is responsible for training workshops and role playing that highlight these issues as part of an overall process of ethical culture enhancement and institutionalization. Despite our findings, hours of ethics training might still be used effectively to enhance employees' ability to recognize an ethical issue. Further, Altman (2010, p. 28) suggests that such training should "provide opportunities for learning new meaning about the harmful consequences of workplace bullying which can lead to better choices of action regarding workplace bullying." After being provided such instruction, employees should be encouraged to blow the whistle if they believe that they are being bullied or others are being mistreated. Ethics codes should also speak out against bullying behaviors and promote teamwork, particularly among sales-oriented employees. Given that subclinical psychopaths tend to limit their bullying behavior to more non-aggressive and manipulative activity in order to protect their social standing, and only then when management is not present, managers need to be attuned to the outcomes of bullying as they are manifested in employees. For example, management should be aware that employees will likely suffer compromised health and exhibit listlessness and fearfulness, which may suggest that they are targets or witnesses of bullying (Lutgen-Sandvik et al. 2007; Parzefall and Salin 2010; Boddy 2017). In addition, psychopaths may be identified because they tend to demand excessive control, try to intimidate 
others, and do not tolerate questioning or any form of dissent (Boddy 2017). These observable cues from employees should trigger managerial recognition of an ethical issue, which in turn should prompt the identification of undesirable patterns of unethical decisions, attitudes, or behaviors directed at fellow employees.

If management successfully identifies bullying behavior, they should take immediate and appropriate action to decrease the misconduct from escalating (Heames et al. 2006; Parzefall and Salin 2010). If management is unable to counsel offending employees in order to successfully modify their behavior, it may be necessary to terminate employees unwilling to change. The competitive culture in the U.S. workforce encourages employees to fight back against bullies to avoid appearing weak (Aquino and Thau 2009; Lutgen-Sandvik et al. 2007), so unchecked bullying behaviors tend to spread quickly throughout the organization, especially if observers perceive that such aggressive behavior is supported by the organization, even if indirectly; the aforementioned bully alliances can also be a significant problem (Hutchison et al. 2009). To shield the organization from becoming characterized by unethical behavior, management must combat this tendency by establishing an ethical culture that advances a zero-tolerance policy against bullying (Heames et al. 2006). Our results underscore that bullying experiences foster learned behaviors of organizational misconduct, and when combined with psychopathic tendencies, produces impaired ethical reasoning. A strong ethical culture that is supported by top management should create an environment that diminishes reciprocal, displaced, and/or learned unethical behaviors, which should both arrest and reverse negative trends over time. Ideally, the ethical environment should be characterized by helping and cooperative behaviors, especially among salespersons (e.g., Jelinek and Ahearne 2006), and it should have a compensation structure that rewards altruism over aggression (Samnani and Singh 2014).

Management also needs to be cognizant of the antecedent conditions that by their very nature create an employment environment of stress and misconduct. Such a workplace can encourage bullying behaviors among coworkers and reduce individual motivations to practice sound ethical reasoning. For example, a work environment characterized by change, personnel adjustments, and uncertainty can produce stress, insecurity, and chaos, which taken together can create a stage where bullying and psychopathy can flourish if unmanaged (Baillien and De Witte 2009; Boddy 2011; Harvey et al. 2009; Hodson et al. 2006; Sweeney 2007; Valentine et al. 2017). Darrat et al. (2010) also found that conflicts between family and employment are associated with different type of deviant behaviors, including interpersonal deviance. Further, many of these factors could cause the ethical context to degenerate into a workplace that causes misconduct to spiral and spill over into other work areas; the findings of Yoo and Frankwick (2013) suggest that emotional exhaustion may occur among salespersons. Managers should keep employees informed of all relevant organizational decisions and fully communicate to employees when changes affect them directly. If these efforts fail to fully mitigate misconduct, recent court rulings indicate that U.S. companies and their employees can be shielded legally from workplace bullying even though there is currently no federal legislation that provides such safeguards (Martin and LaVan 2010).

\section{Contributions, Limitations, and Future Research}


This study makes important and significant contributions to the literature by identifying unique connections among bullying, psychopathy, and the recognition of an ethical issue, a critical step in the ethical reasoning process. If one cannot recognize an ethical dilemma, one cannot engage in ethical reasoning to properly negotiate workplace interrelationships. Deviant interactions with coworkers can indeed trigger spiraling misconduct that erodes the ethical context, curtails effective customer service, and suppresses organizational profits. Overall, the findings of this study provide understanding of how psychopathy mediates bullying experiences and ethical issue recognition in a manner that likely precipitates a toxic work culture.

While this study provides clarity regarding the relationships among bullying, psychopathy, and recognition of an ethical issue, there are a number of research limitations that should be noted. For example, because this is a cross-sectional study, we can only address correlations and associations, meaning that the study design does not permit us to make conclusions about causality. It is possible that poor ethical decision making and the negative behaviors associated with psychopathy create the appropriate conditions for a spiraling/spillover of workplace bullying. Further, our recognition of an ethical issue variable is a single-item measure that we employed due to survey length and response rate concerns; however, Diamantopoulos et al. (2012) provided support for our use of this single-item measure of ethical issue recognition. Because we gathered a national sample that necessitated two waves of responses, nonresponse bias could have been a problem given the relatively modest response rate. However, we tested for this possibility, and results suggested this was not a serious concern. Also, given the survey nature of this cross-sectional study, common method bias was also a concern, but again tests suggested that this was not a serious issue. Since the study addressed highly sensitive issues relating to psychopathy and bullying, it is likely some respondents presented themselves in a more ethical or socially desirable manner, which necessitated that social desirability be specified as a control in the models. Due to a low response rate, we were compelled to gather additional data using a convenience sampling technique. Subjects agreeing to participate may therefore possess more helpful tendencies than those in the general population, thus influencing the findings. We also caution against generalizing the results to other unrepresented populations since the context of the study focused on a sample of selling and business employees. Recognition of an ethical issue for businesspeople might be different from other workers.

Future research should investigate how bullying experiences and psychopathy affect other components of ethical reasoning. For example, psychopathy might also mediate the relationship between workplace bullying and other decision-making steps such as ethical judgment, intention, and behavior (Rest 1986). It would also be interesting for future research to vary the type of bullying behavior to include more aggressive forms of misconduct, rather than the more latent forms investigated in this study. We also suggest that future research incorporate differing business samples as participants. For example, determining whether the findings are consistent for accounting/finance and human resource professionals would be particularly useful given the misconduct that can occur in these fields. These additional investigations, when combined with this study's findings, can further contribute to understanding of the complex interactions of workplace bullying, psychopathy, and ethical decision making. 


\section{Footnotes}

1. The questionnaire was reviewed by two professors with strong reputations in business ethics and sustainability.

2. Our conjecture is that the low response rate was driven by the very sensitive nature of the study that required participants to reflect about bullying behaviors they may have experienced.

3. While it is generally advisable to employ multiple-item measures rather than single-item measures, we were concerned with survey length and response-rate issues, thus prompting us to employ a more global single-item measure for recognition of an ethical issue. In support of this strategy, we cite Diamantopoulos et al. (2012, pp. 444-446), who contended that researchers are justified in employing single-item measures when 1) small sample sizes are expected due to budgetary and/or subject recruitment challenges, 2) the research is exploratory in nature, and 3 ) the construct is widely-understood and may therefore be meaningfully measured using a single item.

4. Full mediation was present because a significant relationship was not identified between perceived workplace bullying and ethical issue recognition in the presence of psychopathy.

\section{Notes}

\section{Acknowledgements}

Funding provided by the University of Wyoming was used to support this research. The authors wish to thank O.C. Ferrell and Eric Arnould for their assistance with the questionnaire and Lynn Godkin for his assistance with data collection.

\section{Compliance with Ethical Standards}

\section{Funding}

This study was not funded by an outside source (it was funded by the University of Wyoming).

\section{Conflict of Interest}

The authors declare they have no conflicts of interest.

\section{Informed Consent}

Participation in this self-report attitude survey was voluntary; participants were only encouraged to complete the questionnaire ("Please complete this "sales relations survey" was used as introductory text on the questionnaire); anonymity and confidentiality were ensured on the 
questionnaire ("Confidential when completed-You will remain anonymous" was included as descriptive text on the questionnaire).

\section{References}

Alexander, C. S., \& Becker, H. J. (1978). The use of vignettes in survey research. Public Opinion Quarterly, 42, 93-104.

Altman, B. A. (2010). Workplace bullying: Application of Novak's (1998) learning theory and implications for training. Employee Responsibilities and Rights Journal, 22, 21-32.

American Psychiatric Association. (APA; 2013). Diagnostic and statistical manual of mental disorders (5th ed.; DSM-V). Washington, DC: Author.

Andersson, L. M., \& Pearson, C. M. (1999). Tit for tat? The spiraling effect of incivility in the workplace. Academy of Management Review, 24, 452-471.

Aquino, K., \& Thau, S. (2009). Workplace victimization: Aggression from the target's perspective. Annual Review of Psychology, 60, 717-741.

Armstrong, J. S., \& Overton, T. S. (1977). Estimating nonresponse bias in mail surveys. Journal of Marketing Research, 14, 396-402.

Babiak, P., \& Hare, R. D. (2006). Snakes in suits: When psychopaths go to work. New York: Regan Books.

Baillien, E., \& De Witte, H. (2009). Why is organizational change related to workplace bullying? Role conflict and job insecurity as mediators. Economic and Industrial Democracy, 30, $348-371$.

Baillien, E., De Cuyper, N., \& De Witte, H. (2011). Job autonomy and workload as antecedents of workplace bullying: A two-wave test of Karasek's job demand control model for targets and perpetrators. Journal of Occupational and Organizational Psychology, 84, 191-208.

Bandura, A. (2006). Social learning theory of aggression. Journal of Communication, 28, 12-29.

Barnett, T. (2001). Dimensions of moral intensity and ethical decision-making: An empirical study. Journal of Applied Social Psychology, 31, 1038-1057.

Barnett, T., \& Valentine, S. (2004). Issue contingencies and marketers' recognition of ethical issues, ethical judgments and behavioral intentions. Journal of Business Research, 57, $338-346$.

Baron, R. A., \& Neuman, J. H. (1998). Workplace aggression-the iceberg beneath the tip of workplace violence: Evidence on its forms, frequency, and targets. Public Administration Quarterly, 21, 446-464. 
Baughman, H. H., Dearing, S., Giammarco, E., \& Vernon, P. A. (2012). Relationships between bullying behaviours and the dark triad: A study with adults. Personality and Individual Differences, 52, 571-575.

Baysinger, M. A., Scherer, K. T., \& LeBreton, J. M. (2014). Exploring the disruptive effects of psychopathy and aggression on group processes and group effectiveness. Journal of Applied Psychology, 99, 48-65.

Blair, R. J. R. (2007). The amygdala and ventromedial prefrontal cortex in morality and psychopathy. Trends in Cognitive Sciences, 11, 387-392.

Boddy, C. R. (2006). The dark side of management decisions: Organisational psychopaths. Management Decision, 44, 1461-1475.

Boddy, C. R. (2011). Corporate psychopaths, bullying, and unfair supervision in the workplace. Journal of Business Ethics, 100, 367-379.

Boddy, C. R. (2014). Corporate psychopaths, conflict, employee affective well-being and counterproductive work behaviour. Journal of Business Ethics, 121, 107-121.

Boddy, C. R. (2017). Psychopathic leadership: A case study of a corporate psychopath CEO. Journal of Business Ethics. published online. https://doi.org/10.1007/s10551-015-2908-6.

Boddy, C. R., Ladyshewsky, R. K., \& Galvin, P. (2010). Leaders without ethics in global business: Corporate psychopaths. Journal of Public Affairs, 10, 121-138.

Bowling, N. A., \& Beehr, T. A. (2006). Workplace harassment from the victim's perspective: A theoretical model and meta-analysis. Journal of Applied Psychology, 91, 998-1012.

Caponecchia, C., Sun, A. Y., \& Wyatt, A. (2012). Psychopaths' at work? Implications of lay persons' use of labels and behavioural criteria for psychopathy. Journal of Business Ethics, 107, 399-408.

Carlson, N. R. (2014). Foundations of behavioral neuroscience. New York, NY: Pearson Education.

Caywood, C. L., \& Laczniak, G. R. (1986). Ethics and personal selling: Death of a Salesman as an ethical primer. Journal of Personal Selling \& Sales Management, 6, 81-88.

Crowne, D. P., \& Marlowe, D. (1960). A new scale of social desirability independent of psychopathology. Journal of Consulting Psychology, 24, 349-354.

Darrat, M., Amyx, D., \& Bennett, R. (2010). An investigation into the effects on work-family conflict and job satisfaction on salesperson deviance. Journal of Personal Selling \& Sales Management, 30, 239-251.

Diamantopoulos, A., Sarstedt, M., Fuchs, C., Wilczynski, P., \& Kaiser, S. (2012). Guidelines for choosing between multi-item and single-item scales for construct measurement: A predictive validity perspective. Journal of the Academy of Marketing Science, 40, 434449. 
Einarsen, S., Raknes, B. I., \& Matthiesen, S. B. (1994). Bullying and harassment at work and their relationships to work environment quality: An exploratory study. The European Work and Organizational Psychologist, 4, 381-401. Employ Respons Rights J (2017) 29:221-244 241

Ferrell, O. C., \& Gresham, L. G. (1985). A contingency framework for understanding ethical decision making in marketing. Journal of Marketing, 49, 87-96.

Ferrell, O. C., Johnston, M. W., \& Ferrell, L. (2007). A framework for personal selling and sales management ethical decision making. Journal of Personal Selling \& Sales Management, 27, 291-299.

Fischer, D. G., \& Fick, C. (1993). Measuring social desirability: Short forms of the MarloweCrowne social desirability scale. Educational and Psychological Measurement, 53, 417424.

Fornell, C., \& Larcker, D. F. (1981). Evaluating structural equation models with unobserved variables and measurement error. Journal of Marketing Research, 18, 39-50.

Giorgi, G. (2012). Workplace bullying in academia creates a negative work environment: An Italian study. Employee Responsibilities and Rights Journal, 24, 261-275.

Giorgi, G., Leon-Perez, J. M., \& Arenas, A. (2015). Are bullying behaviors tolerated in some cultures? Evidence for a curvilinear relationship between workplace bullying and job satisfaction among Italian workers. Journal of Business Ethics, 131, 227-237.

Hair, J. F., Anderson, R. D., Tatham, R. L., \& Black, W. C. (1998). Multivariate data analysis. New Jersey: Prentice Hall.

Hare, R. (1994). Predators: The disturbing world of the psychopaths among us. Psychology Today, 27(1), 54-63.

Hare, R. (1999a). Psychopathy as a risk factor for violence. Psychiatric Quarterly, 70(3), 181197.

Hare, R. (1999b). Without conscience: The disturbing world of the psychopaths among us. New York: Guildford Press.

Harvey, M., Treadway, D. C., \& Heames, J. T. (2007). The occurrence of bullying in global organizations: A model and issues associated with social/emotional contagion. Journal of Applied Social Psychology, 37, 2576-2599.

Harvey, M. G., Treadway, D., Heames, J. T., \& Duke, A. (2009). Bullying in the 21st century global organization: An ethical perspective. Journal of Business Ethics, 85, 27-40.

Hauge, L. J., Skogstads, A., \& Einarsen, S. (2009). Individual and situational predictors of workplace bullying: Why do perpetrators engage in the bullying of others? Work and Stress, 23, 349-358. 
Heames, J. T., Harvey, M. G., \& Treadway, D. (2006). Status inconsistency: An antecedent to bullying behavior in groups. International Journal of Human Resource Management, 17, 348-361.

Hodson, R., Roscigno, V. J., \& Lopez, S. H. (2006). Chaos and the abuse of power: Workplace bullying in organizational and interactional context. Work and Occupations, 33, 382-416.

Hoffman, K. D., Howe, V., \& Hardigree, D. W. (1991). Ethical dilemmas faced in the selling of complex services: Significant others and competitive pressures. Journal of Personal Selling \& Sales Management, 11, 13-25.

Hunt, S. D., \& Vitell, S. J. (2006). A general theory of marketing ethics: A revision and three questions. Journal of Macromarketing, 26, 1-11.

Hutchison, M., Vickers, M. H., Wilkes, L., \& Jackson, D. (2009). "the worse you behave, the more you seem, to be rewarded": Bullying in nursing as organizational corruption. Employee Responsibilities and Rights Journal, 21, 213-229.

Jackson, R. W., Wood, C. M., \& Zboja, J. J. (2013). The dissolution of ethical decision-making in organizations: A comprehensive review and model. Journal of Business Ethics, 116, 233-250.

Jelinek, R., \& Ahearne, M. (2006). The enemy within: Salesperson deviance and its determinants. Journal of Personal Selling \& Sales Management, 26, 327-344.

Jones, T. M. (1991). Ethical decision-making by individuals in organizations: An issuecontingent model. Academy of Management Review, 16, 366-395.

LeBreton, J. M., Binning, J. F., \& Adorno, A. J. (2006). Subclinical psychopaths. Comprehensive handbook of personality and psychopathology, 1, 388-411.

Levashina, J., \& Campion, M. A. (2009). Expected practices in background checking: Review of the human resource management literature. Employee Responsibilities and Rights Journal, 21, 231-249.

Levenson, M. R., Kiehl, K. A., \& Fitzpatrick, C. M. (1995). Assessing psychopathic attributes in a noninstitutionalized population. Journal of Personality and Social Psychology, 68, $151-158$.

Lutgen-Sandvik, P., Tracy, S. J., \& Alberts, J. K. (2007). Burned by bullying in the American workplace: Prevalence, perception, degree and impact. Journal of Management Studies, 44, 837-862.

Lynam, D. R., Whiteside, S., \& Jones, S. (1999). Self-reported psychopathy: A validation study. Journal of Personality Assessment, 73, 110-132.

Lynam, D. R., Caspi, A., Moffitt, T. E., Loeber, R., \& Stouthamer-Loeber, M. (2007). Longitudinal evidence that psychopathy scores in early adolescence predict adult psychopathy. Journal of Abnormal Psychology, 116, 155-165. 
Martin, W., \& LaVan, H. (2010). Workplace bullying: A review of litigated cases. Employee Responsibilities and Rights Journal, 22, 175-194.

Matthiesen, S. B., \& Einarsen, S. (2007). Perpetrators and targets of bullying at work: Role of stress and individual differences. Violence and Victims, 22, 735-753.

Mayhew, C., McCarthy, P., Chappell, D., Quinlan, M., Barker, M., \& Sheehan, M. (2004). Measuring the extent of impact from occupational violence and bullying on traumatized workers. Employee Responsibilities and Rights Journal, 16, 117-134.

McKay, R., Arnold, D. H., Fratzi, J., \& Thomas, R. (2008). Workplace bullying in academia: A Canadian study. Employee Responsibilities and Rights Journal, 20, 77-100.

Mikkelsen, E. G., \& Einarsen, S. (2001). Bullying in Danish work-life: Prevalence and health correlates. European Journal of Work and Organizational Psychology, 10, 393-413.

Nathanson, C., Paulhus, D. L., \& Williams, K. M. (2006). Predictors of a behavioral measure of scholastic cheating: Personality and competence but not demographics. Contemporary Educational Psychology, 31, 97-122.

Neumann, C. S., \& Hare, R. D. (2008). Psychopathic traits in a large community sample: Links to violence, alcohol use, and intelligence. Journal of Consulting and Clinical Psychology, $76,893-899$.

Nielsen, M. B., \& Einarsen, S. (2012). Outcomes of exposure to workplace bullying: A metaanalytic review. Work and Stress, 26, 309-332.

Novak, J. D. (1998). Learning, creating, and using knowledge: Concept maps ${ }^{\mathrm{TM}}$ as facilitative tools in schools and corporations. Mahwah: Lawrence Erlbaum.

O'Boyle Jr., E. H., Forsyth, D. R., Banks, G. C., \& McDaniel, M. A. (2012). A meta-analysis of the dark triad and work behavior: A social exchange perspective. Journal of Applied Psychology, 97, 557-579.

Parzefall, M., \& Salin, D. M. (2010). Perceptions of and reactions to workplace bullying: A social exchange perspective. Human Relations, 63, 671-780.

Paulhus, D. L., \& Williams, K. M. (2002). The dark triad of personality: Narcissism, Machiavellianism, and psychopathy. Journal of Research in Personality, 36, 556-563.

Pearson, C. M., Andersson, L. M., \& Porath, C. L. (2000). Assessing and attacking workplace incivility. Organizational Dynamics, 29, 123-137.

Pilch, I., \& Turska, E. (2015). Relationships between Machiavellianism, organizational culture, and workplace bullying: Emotional abuse from the target's and the perpetrator's perspective. Journal of Business Ethics, 128, 83-93.

Podsakoff, P. M., MacKenzie, S. B., Lee, Y., \& Podsakoff, N. P. (2003). Common method biases in behavioral research: A critical review of the literature and recommended remedies. Journal of Applied Psychology, 88, 879-903. 
Power, J. L., Brotheridge, C. M., Blenkinsopp, J., Bowes-Sperry, L., Bozionelos, N., Buzady, Z., Chuang, A., Drnevich, D., Garzon-Vico, A., Leighton, C., Madero, S. M., Mak, W., Mathew, R., Monserrat, S. I., Mujtaba, B. G., Olivas-Lujan, M. R., Polycroniou, P., Sprigg, C. A., Axtell, C., Holman, D., Ruiz-Gutierrez, N., \& A. U. O. (2013). Acceptability of workplace bullying: A comparative study of six continents. Journal of Business Research, 66, 374-380.

Randall, F., \& Fernandes, M. F. (1991). The social desirability response bias in ethics research. Journal of Business Ethics, 10(11), 805-817.

Rauthmann, J. F., \& Kolar, G. P. (2012). How “dark" are the dark triad traits: Examining the perceived darkness of narcissism, Machiavellianism, and psychopathy. Personality and Individual Differences, 53, 884-889.

Reidenbach, R. E., \& Robin, D. P. (1990). Toward the development of a multidimensional scale for improving evaluations of business ethics. Journal of Business Ethics, 9, 639-653.

Rest, J. R. (1986). Moral development: Advances in research and theory. New York: Praeger.

Robin, D. P., Reidenbach, R. E., \& Forrest, P. J. (1996). The perceived importance of an ethical issue as an influence on the ethical decision-making of ad managers. Journal of Business Research, 35, 17-28.

Salin, D. (2001). Prevalence and forms of bullying among business professionals: A comparison of two different strategies for measuring bullying. European Journal of Work and Organizational Psychology, 10, 425-441.

Salin, D. (2003). Ways of explaining workplace bullying: A review of enabling, motivating, and precipitating structures and processes in the work environment. Human Relations, 56, 1213-1232.

Samnani, A. K., \& Singh, P. (2012). 20 years of workplace bullying research: A review of the antecedents and consequences of bullying in the workplace. Aggression and Violent Behavior, 17, 581-589.

Samnani, A. K., \& Singh, P. (2014). Performance-enhancing compensation practices and employee productivity: The role of workplace bullying. Human Resource Management Review, 24, 5-16.

Saunders, P., Huynh, A., \& Goodman-Delahunty, J. (2007). Defining workplace bullying behaviour professional lay definitions of workplace bullying. International Journal of Law and Psychiatry, 30, 340-354.

Seevers, M. T., Skinner, S. J., \& Kelley, S. W. (2007). A social network perspective on sales force ethics. Journal of Personal Selling \& Sales Management, 27, 341-353.

Serviere-Munoz, L., \& Mallin, M. L. (2013). How do unethical salespeople sleep at night? The role of neutralizations in the justification of unethical sales intentions. Journal of Personal Selling \& Sales Management, 33, 289-306. 
Smith, S. F., \& Lilienfeld, S. O. (2013). Psychopathy in the workplace: The knowns and unknowns. Aggression and Violent Behavior, 18, 204-218. Employ Respons Rights J (2017) 29:221-244 243

Stevens, G. W., Deuling, J. K., \& Armenakis, A. A. (2012). Successful psychopaths: Are they unethical decisionmakers and why? Journal of Business Ethics, 105, 139-149.

Strahan, R., \& Gerbasi, K. C. (1972). Short, homogeneous versions of the Marlowe-Crowne social desirability scale. Journal of Clinical Psychology, 28, 191-193.

Sweeney, P. (2007). Organizational chaos and relative powerlessness: Breeding ground for bullies? Academy of Management Perspectives, 21, 77-78.

Tellefsen, T., \& Eyuboglu, N. (2002). The impact of a salesperson's in-house conflicts and influence attempts on buyer commitment. Journal of Personal Selling \& Sales Management, 22, 157-172.

Treviño, L. K. (1986). Ethical decision making in organizations: A person-situation interaction model. Academy of Management Review, 11, 601-617.

Valentine, S., \& Barnett, T. (2007). Perceived organizational ethics and the ethical decision of sales and marketing personnel. Journal of Personal Selling and Sales Management, 27, 373-388.

Valentine, S., Fleischman, G., Sprague, R., \& Godkin, L. (2010). Exploring the ethicality of firing employees who blog. Human Resource Management, 49, 87-108.

Valentine, S., Fleischman, G., \& Godkin, L. (2015). Rogues in the ranks of selling organizations: Using corporate ethics to manage workplace bullying and job satisfaction. Journal of Personal Selling \& Sales Management, 35, 143-163.

Valentine, S., Fleischman, G., \& Godkin, L. (2017). Villains, victims, and verisimilitudes: An exploratory study of unethical corporate values, bullying experiences, psychopathy, and selling professionals' ethical reasoning. Journal of Business Ethics. published online. https://doi.org/10.1007/s10551-015-2993-6.

Vega, G., \& Comer, D. R. (2005). Sticks and stones may break your bones, but words can break your spirit: Bullying in the workplace. Journal of Business Ethics, 58, 101-109.

Vickers, M. H. (2014). Towards reducing the harm: Workplace bullying as workplace corruption - a critical review. Employee Responsibilities and Rights Journal, 26, 95-113.

Wotruba, T. R. (1990). A comprehensive framework for the analysis of ethical behavior, with a focus on sales organizations. Journal of Personal Selling \& Sales Management, 10, 29 42.

Yildirim, B. O., \& Derksen, J. L. (2015). Clarifying the heterogeneity in psychopathic samples: Towards a new continuum of primary and secondary psychopathy. Aggression and Violent Behavior, 24, 9-41. 
Yoo, J., \& Frankwick, G. L. (2013). Exploring the impact of social undermining on salesperson deviance: An integrated model. Journal of Personal Selling \& Sales Management, 33, 79-90.

Zabrodska, K., \& Kveton, P. (2013). Prevalence and forms of workplace bullying among university employees. Employee Responsibilities and Rights Journal, 25, 89-108. 